\title{
A Comprehensive Modeling Study on Regional Climate Model (RCM) Application - Regional Warming Projections in Monthly Resolutions under IPCC A1B Scenario
}

\author{
Mohammad Adnan Rajib * and Md. Mujibur Rahman \\ Department of Civil Engineering, Bangladesh University of Engineering and Technology (BUET), \\ Dhaka 1000, Bangladesh; E-Mail: mujib@ce.buet.ac.bd \\ * Author to whom correspondence should be addressed; E-Mail: adnanrajib@ce.buet.ac.bd; \\ Tel.: +880-192-761-2181; Fax: +880-2-966-5639.
}

Received: 10 August 2012; in revised form: 25 September 2012 / Accepted: 2 October 2012 / Published: 31 October 2012

\begin{abstract}
Some of the major dimensions of climate change include increase in surface temperature, longer spells of droughts in significant portions of the world, associated higher evapotranspiration rates, and so on. It is therefore essential to comprehend the future possible scenario of climate change in terms of global warming. A high resolution limited area Regional Climate Model (RCM) can produce reasonably appropriate projections to be used for climate-scenario generation in country-scale. This paper features the development of future surface temperature projections for Bangladesh on monthly resolution for each year from 2011 to 2100 applying Providing Regional Climates for Impacts Studies (PRECIS), and it explains in detail the modeling processes including the model features, domain size selection, bias identification as well as construction of change field for the concerned climatic variable, in this case, surface temperature. PRECIS was run on a $50 \mathrm{~km}$ horizontal grid-spacing under the Intergovernmental Panel on Climate Change (IPCC) A1B scenario and it was found to perform reasonably well in simulating future surface temperature of Bangladesh. The linear regression between observed and model simulated results of monthly average temperatures, within the 30-year period from 1971 to 2000 , gives a high correlation of 0.93 . The applied change field in average annual temperature shows only $0.5{ }^{\circ} \mathrm{C}-1{ }^{\circ} \mathrm{C}$ deviation from the observed values over the period from 2005 to 2008. Eventually, from the projected average temperature change during the years 1971-2000, it is apparent that warming in Bangladesh prevails invariably every month, which might eventually result in an average annual increase of $4{ }^{\circ} \mathrm{C}$ by the year 2100. Calculated anomalies in country-average annual temperature mostly remain on the
\end{abstract}


positive side throughout the period of 2071-2100 indicating an overall up-shift. Apart from these quantitative analyses of temporal changes of temperature, this paper also illustrates their spatial distribution with a view to identify the most vulnerable zones under consequent warming through future times.

Keywords: Bangladesh; climate change; coastal region; RCM; PRECIS; temperature

\section{Introduction}

Climate change has been escalating over recent centuries, causing a great impact on the ecosystem of the earth's surface. The historical climate change along with the present rate of change has influenced engineers to project the future climate change to aid policy makers in making decisions. According to the assessment reports of the Intergovernmental Panel on Climate Change (IPCC), South Asia is one of the most vulnerable regions of the world to climate change impacts [1]. The international community also recognizes that Bangladesh, a South-Asian country, ranks high in the list of most climate-vulnerable countries on Earth. Bangladesh is located between $20^{\circ}$ to $26^{\circ} \mathrm{N}$ and $88^{\circ}$ to $92^{\circ} \mathrm{E}$. Currently, the average temperature of Bangladesh ranges from $17{ }^{\circ} \mathrm{C}$ to $20.6{ }^{\circ} \mathrm{C}$ during winter and $26.9{ }^{\circ} \mathrm{C}$ to $31.1^{\circ} \mathrm{C}$ during summer [2]. The average annual temperature of Bangladesh is expected to increase by $1.4 \pm 0.6{ }^{\circ} \mathrm{C}$ by 2050 [3] and the average monthly temperature might continue to rise invariably every month. Increase in temperature during the months with less precipitation as a result of climate change will increase evapotranspiration and create situations like water loss from soil and resultant reduced crop yield, lower levels of water both in surface and ground water systems, higher microbial concentration and growth rate in the surface waters and so on. If not checked in time, the exacerbating aridity and accompanying desertification processes as a consequence of increased surface temperature are destined to cause severe environmental degradation in different parts of the country.

Climate models are considered as the main tools available for developing projections of climate change in the future $[4,5]$. To "run" a climate model means to divide the planet into a three-dimensional grid, apply the basic equations and evaluate the results at individual grid points. General Circulation Models (GCMs) run typically on a horizontal resolution of around $200 \mathrm{~km}$ or even more. The predictions of coupled Atmosphere-Ocean GCMs (AOGCMs) might be adequate for areas where the terrain is reasonably flat, uniform and away from coasts. But in areas like Bangladesh where coasts of the Bay of Bengal and the Himalayan Mountain have significant effects on weather, General Circulation Models (GCMs) might be unable to capture the local level details needed for assessing climate change impacts at national and regional scales. Also, at the coarse resolution of GCMs, meso-scale atmospheric circulations are either not captured or their intensities are unrealistic. A Regional Climate Model (RCM), therefore, is a good tool for dynamic downscaling of climate features in case of obtaining detailed information for a particular region [6]. A regional model, also known as 'limited-area model' generally covers a specific area of the globe at a higher resolution (typically around $50 \mathrm{~km}$ ) for which conditions at its boundary are specified from an AOGCM [6,7]. The RCM is better able to resolve meso-scale forcings associated with coastlines, mountains, lakes, and vegetation characteristics that exert a strong influence on the local climate [8]. 
A significant number of studies have been conducted using RCM PRECIS over South-Asian countries including Bangladesh [8-11]. Islam et al. [9] shows the future changes in the frequency of warm and cold spells over Pakistan simulated by PRECIS in an IPCC A2 scenario. PRECIS simulations for India by Rupa Kumar et al. [10] authenticate that extremes in maximum and minimum temperatures are expected to increase in the future both under A2 and B2 scenarios, but the night temperatures are increasing faster than the day temperatures. However, the current generation of RCMs like PRECIS still exhibit significant biases for important climate variables such as temperature and precipitation [12]. It is not likely that there is a unique explanation for the climate model projections, and they are not actual predictions. But the point is that, while climate models currently offer one possible explanation for climate change, they are by any means not the only possible ones at present.

\section{Analyzing Current Temperature Conditions in Bangladesh}

The current temperature condition in Bangladesh needs to be analyzed, as it can be reflective of the possible future trend of warming. Average temperature data of every year from 1948 to 2009 are available on a monthly basis from the Bangladesh Meteorological Department (BMD). These temperature values are the average of the observations from 35 observatory stations all over the country, representing the overall temperature condition of Bangladesh at any particular period. As summarized in Table 1, the comparison of the annual average temperatures of 20 years (1953-1972) of record and more recent 20 years (1985-2004) shows an increase of $0.68{ }^{\circ} \mathrm{C}$. The plotted data in Figure 1 shows the recorded average annual temperatures of Bangladesh since 1948 up until to 2009, indicating a prominent overall increase in temperature levels over the past years, with greater warming in recent times. A distinct negative trend or cooling is visible from 1980, which clearly lead to the relatively high rate of temperature increase in the most recent 20 years since 1990 to 2009 (about $0.4{ }^{\circ} \mathrm{C}$ per decade). However, if the average annual temperature of only the last 10 years (2000-2009) is segregated and therefore analyzed, it can is revealed that this rate of temperature increment is even higher and there has been an almost $1{ }^{\circ} \mathrm{C}$ increase since 2000 .

Figure 1. Observed average annual temperatures in Bangladesh (1948-2009).

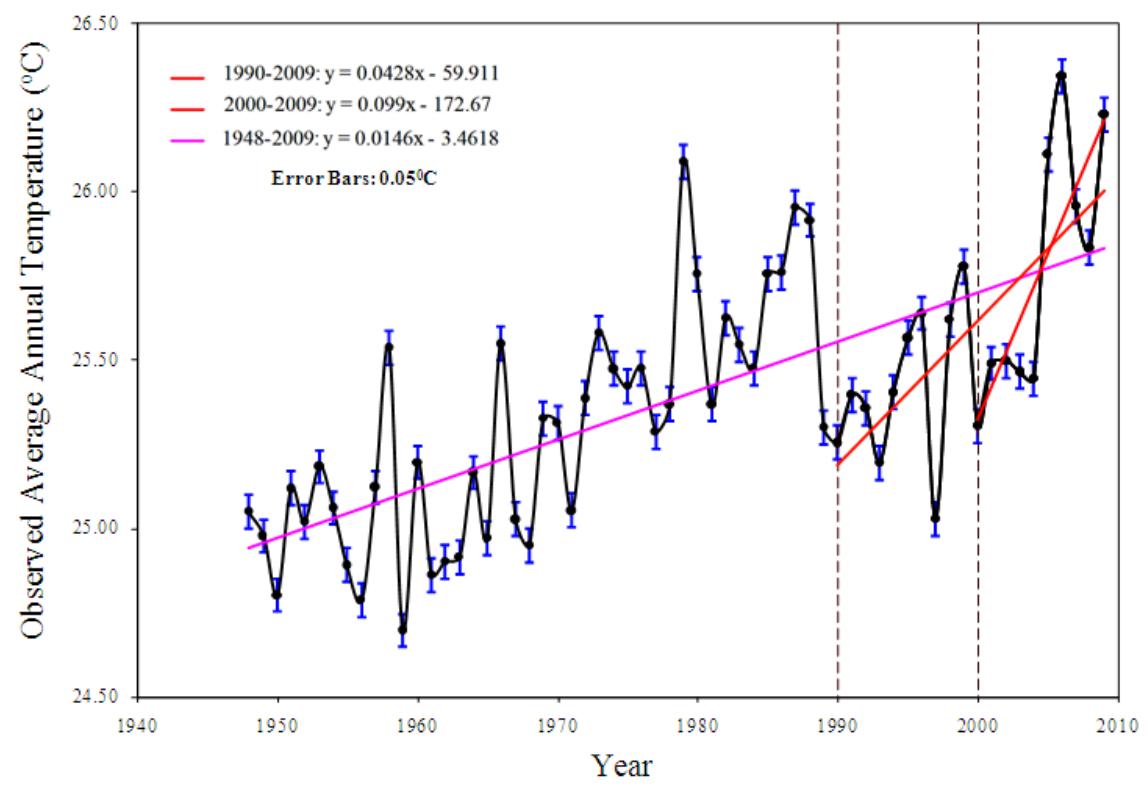


Table 1. Recorded temperature change over the years 1953-2004.

\begin{tabular}{ccc}
\hline Averaging Period & Year & Average Annual Temperature $\left({ }^{\circ} \mathbf{C}\right)$ \\
\hline \multirow{3}{*}{ 10 year average } & $1995-2004$ & 25.9 \\
& $1953-1962$ & 25.1 \\
& Change & +0.72 \\
\hline \multirow{3}{*}{ 20 year average } & $1985-2004$ & 25.9 \\
& $1953-1972$ & 25.2 \\
& Change & +0.68 \\
\hline
\end{tabular}

\section{Modeling Study Using RCM PRECIS}

\subsection{PRECIS: Model Description}

The PRECIS (Providing Regional Climates for Impacts Studies) is a hydrostatic, primitive equation grid point model containing 19 levels described by a hybrid vertical coordinate with the option of downscaling down to a $25 \mathrm{~km}$ resolution $[13,14]$. A more complete description of PRECIS is provided by Jones et al. [6]. In this research, the adopted version of PRECIS (PRECIS 1.7.1) is run on $50 \mathrm{~km}$ horizontal grids having a $0.44^{\circ} \times 0.44^{\circ}$ (latitude $\times$ longitude) resolution $[8,15]$. The entire simulation (1971 to 2100) is segregated into non-overlapping 10 year periods (for example, 1970 to 1979 or 2040 to 2049). First year outputs are discarded every time in consideration of the RCM spin-up period and therefore need to be recalculated by simulating another continuous period that is shifted compared to the first one. The whole process is driven by lateral boundary conditions from the HadCM3Q GCM $[15,16]$.

Output is extracted for surface temperatures at a $1.5 \mathrm{~m}$ elevation whereas the observations are made at a height of $2 \mathrm{~m}$ [13]. Corrections are likely to be necessary for such disagreements, although previous relevant research on Bangladesh does not contain any of the possible correction approaches.

\subsection{Selection of RCM Domain}

One of the major problems of applying an RCM over a region is to determine a suitable domain, which can successfully represent the meteorological parameters of that area. Domain size largely influences RCM outputs. A general criterion for the choice of a regional model domain is difficult and the choice depends on the region, the experimental design and the intended use of the RCM results $[17,18]$. The following conditions are necessary to ensure physical consistency between the PRECIS solution and the pre-determined AOGCM solution external to the RCM domain: (i) if a domain is too large, the model's interior flow may drift away from the large-scale flow of the driving dataset [6]; the domain should be small enough so that the deviation of RCM circulation from the driving AOGCM is not overwhelmingly large [8], (ii) too small a domain exaggeratedly constrains interior dynamics, preventing the model from generating an appropriate response to interior meso-scale circulations and surface conditions [10,19-21].

Therefore, while applying PRECIS for Bangladesh, there is a certain need to choose an optimum domain, which can represent Bangladesh's climate more realistically. Bhaskaran et al. [21] conducted a RCM-domain size experiment over India and determined an optimum domain, known as 'Indian 
domain', with a size of $114 \times 92$ pixels which is quite large for Bangladesh. Islam et al. [22] illustrated four trial-domains for Bangladesh with different sizes that were reviewed prior to this study. A small domain might be helpful by reducing computational time and effort in case of very fine resolution $(25 \mathrm{~km})$ simulation purposes. The major objective of such a pre-simulation trial-domain analysis is to validate whether a smaller domain is sufficient to represent the meteorological conditions occurring as they would in a larger domain, therefore substantially reducing the computational resources.

Figure 2 shows the schematization of the PRECIS domain over Bangladesh that finally was adopted in this research. The selected PRECIS domain consists of $50 \mathrm{~km}$ spaced grids $(\mathrm{dx}=\mathrm{dy})$. A rim of eight pixels along the boundary is basically the GCM-integration "Buffer Area" which is ultimately excluded from the analysis. Model-outputs of average surface temperatures at a $1.5 \mathrm{~m}$ elevation in monthly time steps were extracted only from the grid points that fall over the geographical area of Bangladesh within the selected PRECIS-domain, and then averaged to obtain country-scale temperature conditions. However, all the projections are made considering an A1B scenario resembling a future world of very rapid economic growth, balanced across energy sources with clean and resource-efficient technology [23].

Figure 2. Schematization of PRECIS domain selection over Bangladesh.
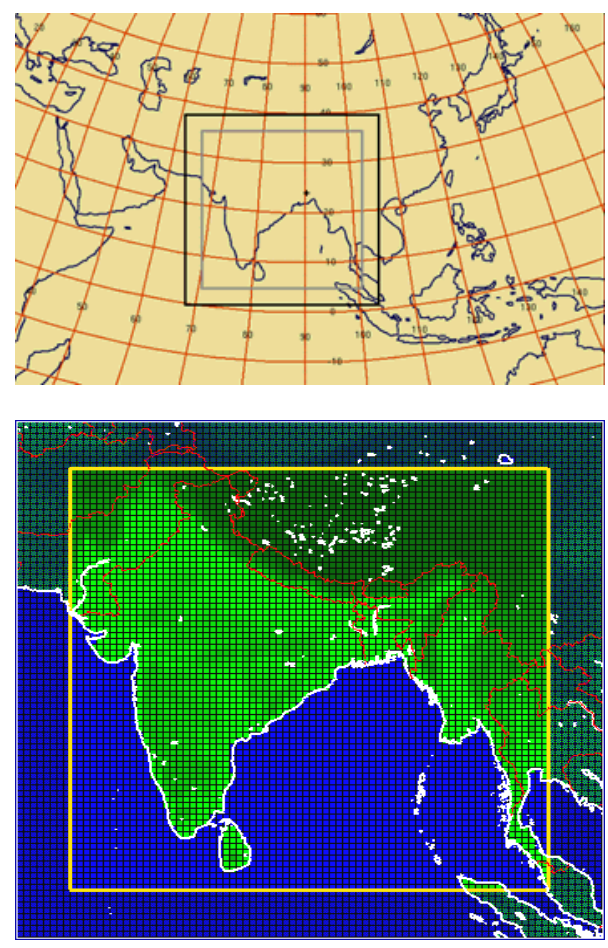

\section{Development of Future Temperature Projections}

\subsection{Model Validation}

Validation provides the deviation of simulation with actual data obtained through observation, which therefore indicates the confidence in projecting the future climate with the model for a region. The RCM PRECIS is validated for Bangladesh through a number of trial simulations. In this paper, PRECIS outputs (A1B scenario) of average monthly temperatures from 1971 to 2000 have been plotted against 
corresponding observed values. Clearly, as shown in Figure 3(a), the extreme lower and higher temperature values remain on the upper half and lower half of the $45^{\circ}$-line, respectively, which denotes that PRECIS outputs exhibit a distinct cold bias in dry seasons and a hot bias in the case of summer months. Of course, a high correlation $(r=0.93)$ prevails between observed data and model outputs.

Figure 3. (a) Regression trend of observed record $v$ s. PRECIS outputs of monthly average temperatures (1971-2000); (b) Comparison of model output and observed data of average temperatures in individual months (1971-2000); (c) Annual temperature cycle based on observed data and applied change field projection (2005-2008); (d) Regression trend of observed data vs. applied change field projections of average monthly temperatures (2005-2008).

(a)

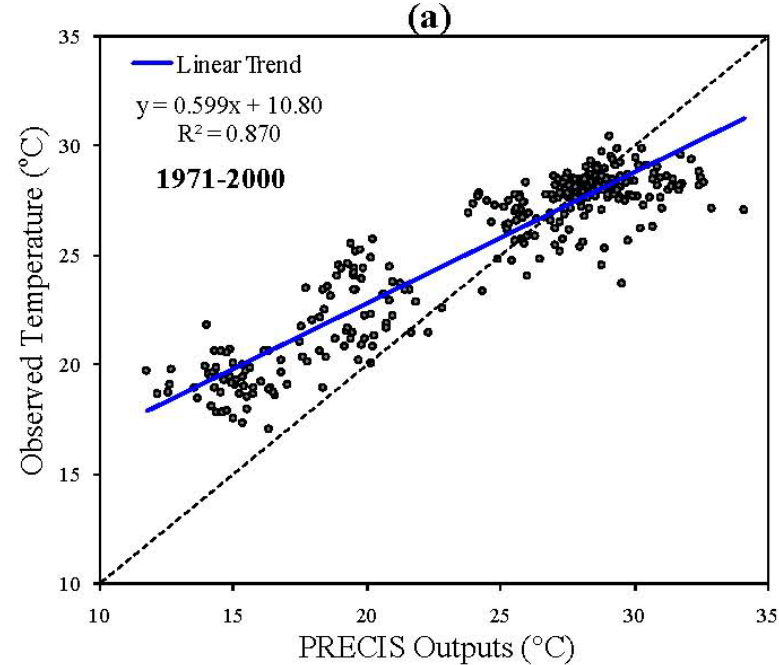

(c)

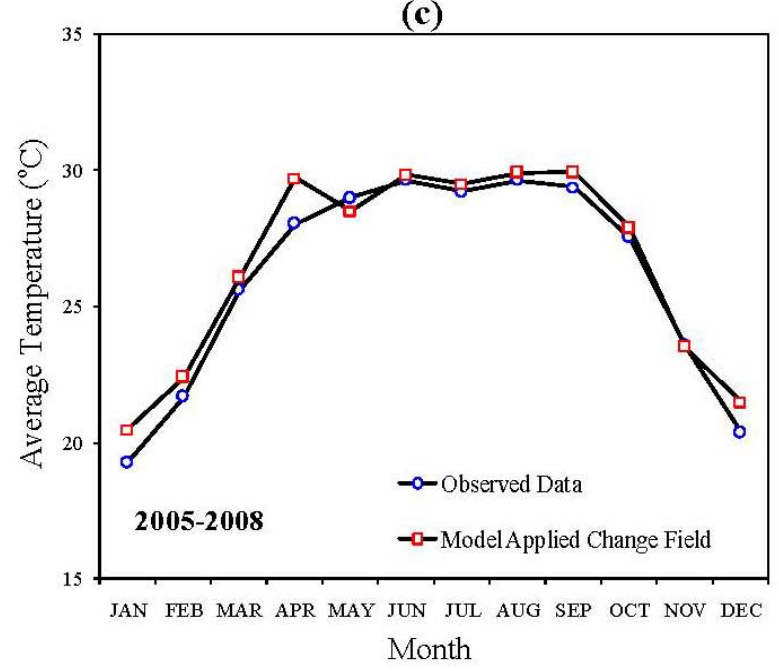

(b)

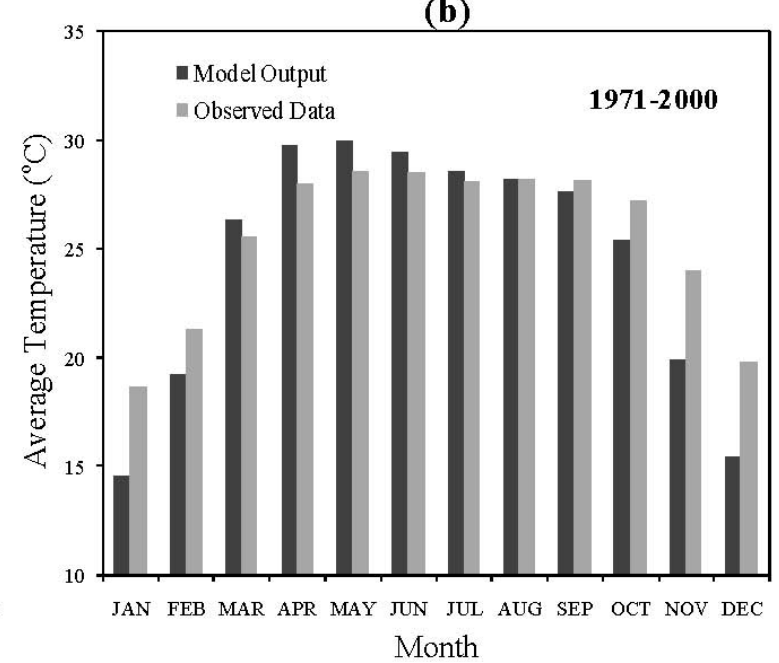

(d)

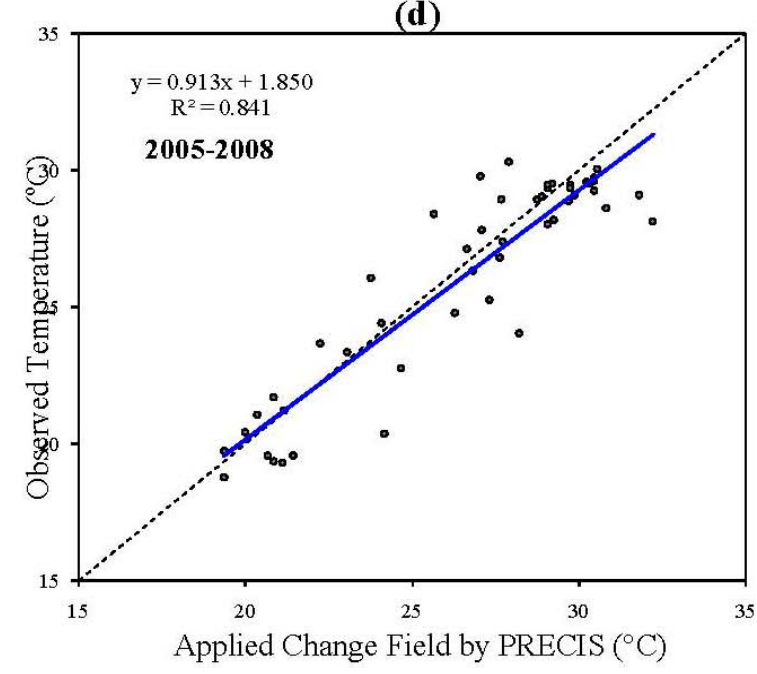

PRECIS was validated by Climate Change Cell (CCC) [24] for 1961-1990 over Bangladesh, and it was found that PRECIS, being run with blsula option [25], gives an average cold bias of $0.61{ }^{\circ} \mathrm{C}$ in annual temperatures for all those years. The "blsula" option likely features the incorporation of the sulfur cycle in the model simulation to understand the role of regional patterns of sulfate aerosols in climate change. Islam et al. [8] showed that there exists a hot bias in monthly averaged temperatures $\left({ }^{\circ} \mathrm{C}\right)$ obtained from PRECIS (blsula) for five months (March to July), while for the rest of the year there exists a cold bias. In that simulation, the model underestimates temperatures by $2.42{ }^{\circ} \mathrm{C}$ and 
$1.96{ }^{\circ} \mathrm{C}$ for winter (DJF) and post-monsoon $(\mathrm{ON})$, respectively. On the other hand, the model overestimates temperatures by $1.21{ }^{\circ} \mathrm{C}$ for summer (MAM), and in monsoon (JJAS) it matches the observed data well with a small deviation of $0.06{ }^{\circ} \mathrm{C}$. Similar attempts for validating PRECIS have also been exercised by Rupa Kumar et al. [10] over the Indian region.

The results shown in Figure 3(b), Tables 2 and 3 further demonstrate the performance of PRECIS in simulating temperatures in Bangladesh under an A1B scenario. Comparisons between model outputs and observed temperature data in individual months over the period of 1971-2000 and their calculated differences again verify that PRECIS has been underestimating post-monsoon dry season (October-February) temperatures, which can be up to the extent of $4{ }^{\circ} \mathrm{C}$ in some months, the deviation being more than $17 \%$ relative to the observed data. However for pre-monsoon and monsoon summer months (March-September), the deviation is much less, $4.67 \%$ and $0.79 \%$, respectively. Such a variation in temperature (i.e., cold bias in the dry season and hot bias in the rainy season) may be due to the decrease and increase of latent heat flux for the two seasons, respectively [26], which may not be well distinguished by the model.

Table 2. Validation of PRECIS for monthly average temperature projections.

\begin{tabular}{ccc}
\hline Month & $\begin{array}{c}\text { 1971-2000 Difference }\left({ }^{\circ} \mathbf{C}\right) \\
\text { (Model Output-Observed Data) }\end{array}$ & $\begin{array}{c}\text { 2005-2008 Difference }\left({ }^{\circ} \mathbf{C} \text { ) }\right. \\
\text { (Applied Change Field-Observed Data) }\end{array}$ \\
\hline JAN & -4.07 & 1.24 \\
FEB & -2.08 & 0.73 \\
MAR & 0.80 & 0.44 \\
APR & 1.72 & 1.70 \\
MAY & 1.36 & -0.48 \\
JUN & 0.94 & 0.19 \\
JUL & 0.47 & 0.29 \\
AUG & 0.00 & 0.28 \\
SEP & -0.52 & 0.53 \\
OCT & -1.83 & 0.36 \\
NOV & -4.07 & -0.05 \\
DEC & -4.38 & 1.12 \\
\hline
\end{tabular}

Table 3. Seasonal average deviation (\%) from observed temperature: (a) calculated for model outputs; (b) calculated for applied change field.

\begin{tabular}{cccccc}
\hline Season & Dry (DJF) & $\begin{array}{c}\text { Pre-Monsoon } \\
\text { (MAM) }\end{array}$ & $\begin{array}{c}\text { Monsoon } \\
\text { (JJAS) }\end{array}$ & $\begin{array}{c}\text { Post-Monsoon } \\
\text { (ON) }\end{array}$ & Annual \\
\hline (a) \% Deviation in 1971-2000 & -17.92 & 4.67 & 0.79 & -11.86 & -3.80 \\
(b) \% Deviation in 2005-2008 & 5.09 & 2.04 & 1.10 & 0.54 & 2.03 \\
\hline
\end{tabular}

\subsection{Development of Future Scenario: "Change Field"}

With variations from actual condition, as analyzed above, RCM outputs cannot be taken as reliable future climate change scenarios. To examine possible future climatic conditions, one prospect is to 
develop projections relative to observed meteorological data [27]. Considering this, projections on average monthly temperatures in individual months for each of the future year from 2011 to 2100 have been developed in this paper with respect to a climatological base-period of 1971-2000. In this method, also known as the "Delta Approach", a scenario of future monthly temperatures is obtained through adjusting the baseline observations by the difference between the results of the RCM control simulation on past baseline years and the corresponding outputs for the future [28]. A pattern of such differences of particular climate output variables is known as a "Change Field" or "Change Factor" [7,29]. Thus, the extent of change and variability in future temperatures is taken from the model simulation directly and applied to the baseline observational data to get a time-series of future temperature scenarios, referred to as the "Applied Change Field" [27,30]. It is conceptually simpler and allows direct the application of the changes on observed records [6,29-31].

Following the "Delta Approach", the applied change field or the constructed future monthly temperature scenario for 2005-2008 is plotted in Figure 3(c), which matches closely the corresponding observed data for most of the months. Therefore, the monthly and seasonal deviations of applied change field data in 2005-2008 relative to the observations drop down significantly compared to the deviations of direct model outputs (Tables 2 and 3). After applying the modeled change field over the baseline observational data, the overall annual deviation is only $2.03 \%$. Also, the linear regression trend between applied change field temperature projection and observed data has been found to align with the $45^{\circ}$-line (Figure $3(\mathrm{~d})$ ), which again signifies a small difference between the projection and recorded temperature.

\subsection{Monthly Trends of Temperature Change}

The PRECIS-projected temperature change (applied change field) in individual months relative to the climatological base period of 1971-2000 has been assembled in Table 4 over three non-overlapping 30 -year future periods. It is evident that the dry winter months in Bangladesh will show relatively more warming in the future, which is analogous to the Multi-Model Data (MMD) projections of IPCC AR4 [32]. The dry season months like December or January might have a greater amount of temperature change (around $5^{\circ} \mathrm{C}$ in 2071-2100) with respect to 1971-2000, compared to the monsoon season months like July (around $3{ }^{\circ} \mathrm{C}$ in 2071-2100). Such a warming might prevail invariably in every month, which would therefore result in an average annual temperature increase of $4{ }^{\circ} \mathrm{C}$ by the year 2100 .

Also, Figure 4 shows the monthly temperature projection by PRECIS (with applied change field) along with the observed data, where all the months show increasing temperature trends. Here again, the dry season months exhibit temperature amplification at a sharper rate. A linear trend for the applied change field projection of January's average temperature can detect an increasing rate of $0.5{ }^{\circ} \mathrm{C}$ per decade from 2011 onwards, whereas in July it can be $0.4{ }^{\circ} \mathrm{C}$. Also, the trends of projected temperature in each season conform well with the observed records. 
Figure 4. PRECIS projections of average monthly temperatures for Bangladesh up to the year 2100 with observed data of 1950-2010.
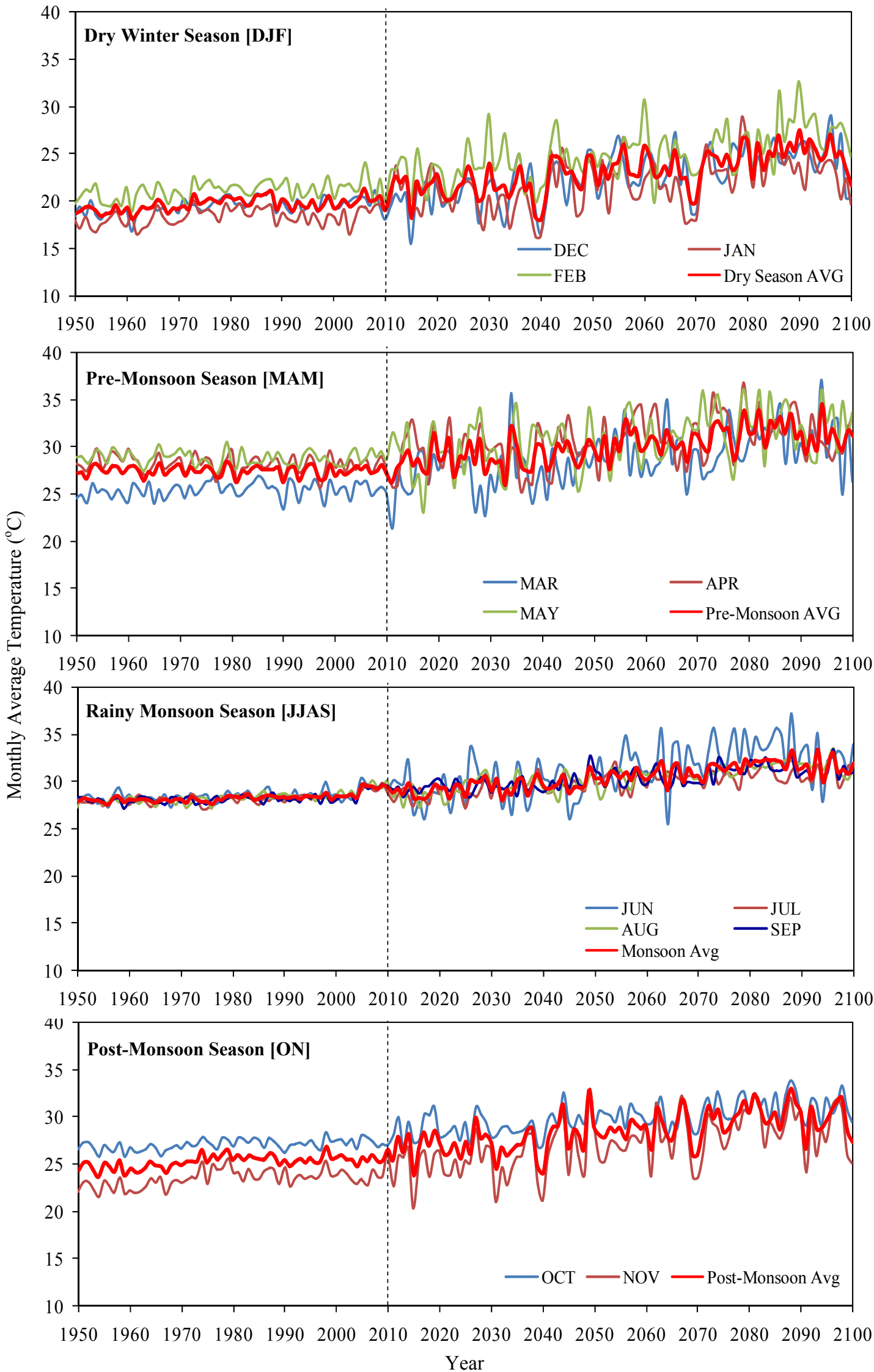
Table 4. Average temperature increase $\left({ }^{\circ} \mathrm{C}\right)$ for Bangladesh relative to $1971-2000$.

\begin{tabular}{|c|c|c|c|c|}
\hline \multirow{2}{*}{ Month } & \multirow{2}{*}{$\begin{array}{c}\text { Observed } \\
1971-2000\end{array}$} & \multicolumn{3}{|c|}{ Temperature Increase $\left({ }^{\circ} \mathrm{C}\right)$} \\
\hline & & 2011-2040 & 2041-2070 & 2071-2100 \\
\hline January & 18.62 & 1.47 & 3.15 & 4.89 \\
\hline February & 21.32 & 1.97 & 3.46 & 5.36 \\
\hline March & 25.58 & 1.5 & 3.24 & 4.77 \\
\hline April & 28.04 & 1.27 & 2.51 & 3.58 \\
\hline May & 28.56 & 1.07 & 2.01 & 3.79 \\
\hline June & 28.50 & 0.95 & 2.48 & 4.57 \\
\hline July & 28.10 & 0.83 & 1.98 & 2.62 \\
\hline August & 28.25 & 1.06 & 2.02 & 3.22 \\
\hline September & 28.14 & 1.22 & 2.12 & 3.2 \\
\hline October & 27.23 & 1.4 & 2.73 & 3.95 \\
\hline November & 23.95 & 1.0 & 3.39 & 4.92 \\
\hline December & 19.78 & 0.78 & 3.07 & 4.7 \\
\hline Annual & 25.51 & 1.21 & 2.68 & 4.13 \\
\hline
\end{tabular}

The temperature anomaly in the baseline of 1971-2000 as well as in the future time-segment of 2071-2100 is calculated. Normalized anomalies of the average annual temperature in 2071-2100 (relative to the baseline period 1971-2000) are obtained by subtracting the temperature in a year within that period from the mean baseline temperature and dividing it by the standard deviation during 1971-2000. The method of moving average is applied to highlight the periodic variations in the anomaly series. A positive anomaly indicates that the observed or model-projected temperature at any particular instance is warmer than the baseline reference value, while a negative anomaly indicates it to be cooler [33]. The resultant annual temperature anomalies (Figure 5) might invariably show a positive increase pattern in 2071-2100 in contradiction with that in the base period.

Figure 5. Calculated anomalies for annual average temperatures (observed and future).

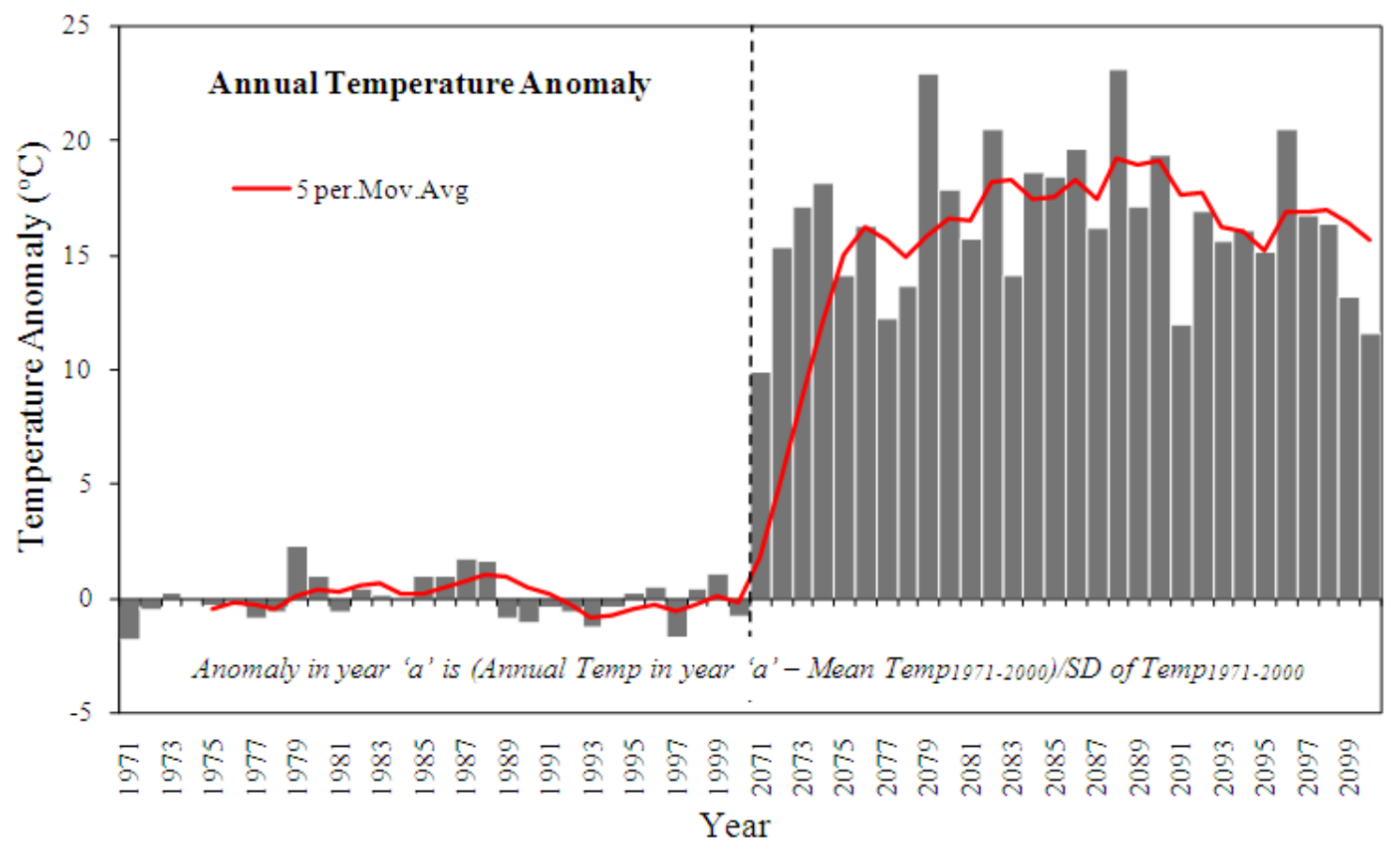


Along with the temporal analysis, the spatial pattern of gradual warming can be of utmost importance. Accordingly, Figures 6 and 7 feature respectively the spatial distribution of average maximum and minimum temperature in January and May along the coastal region of Bangladesh, with comparison between baseline data (1971-2000) and the model outputs for future years (2071-2100).

Figure 6. Spatial distribution of average maximum temperature in January and May ((top) and (bottom)): comparison between baseline (1971-2000) and simulated future (2071-2100).
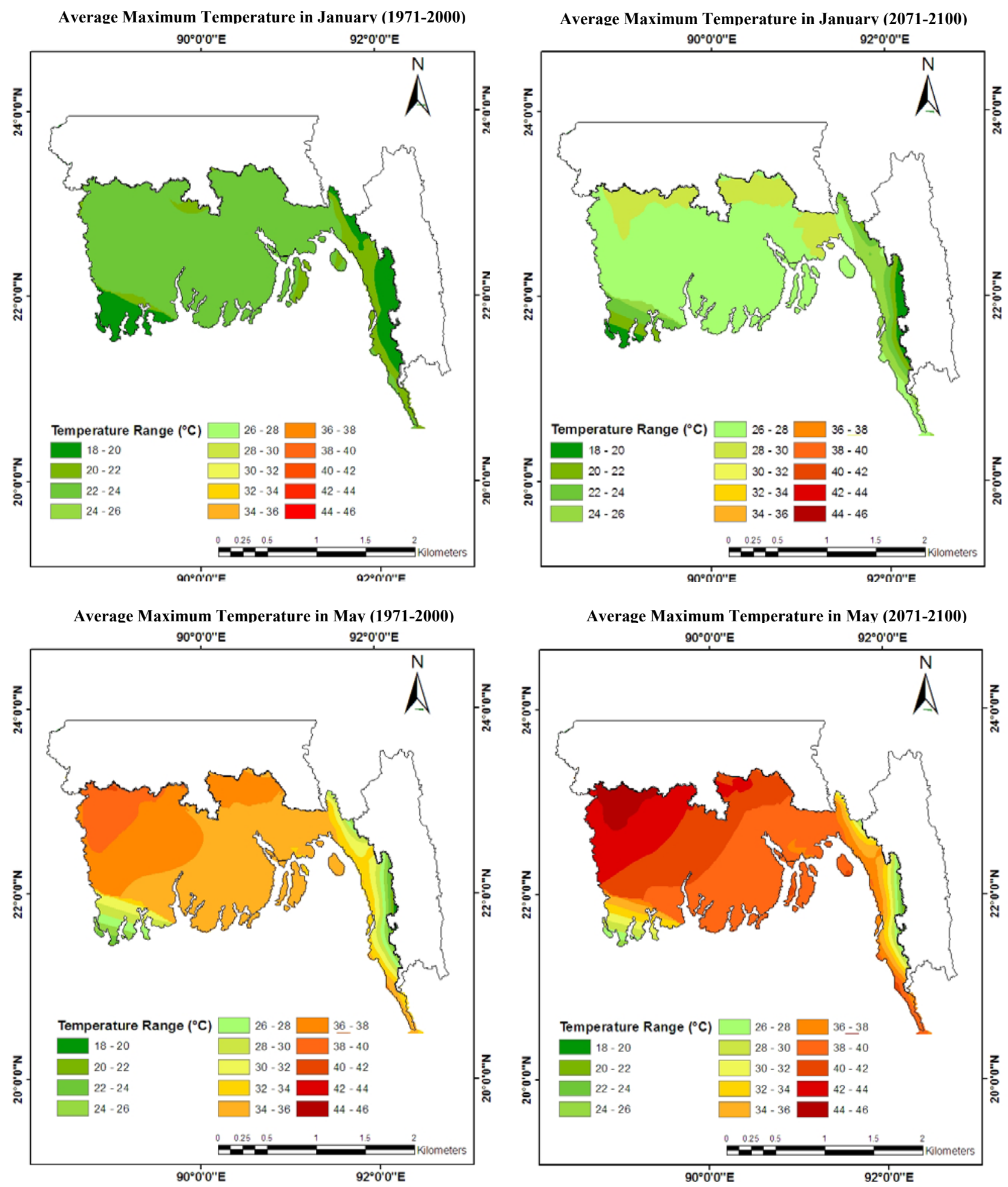
Figure 7. Spatial distribution of average minimum temperature in January and May ((top) and (bottom)): comparison between baseline (1971-2000) and simulated future (2071-2100).
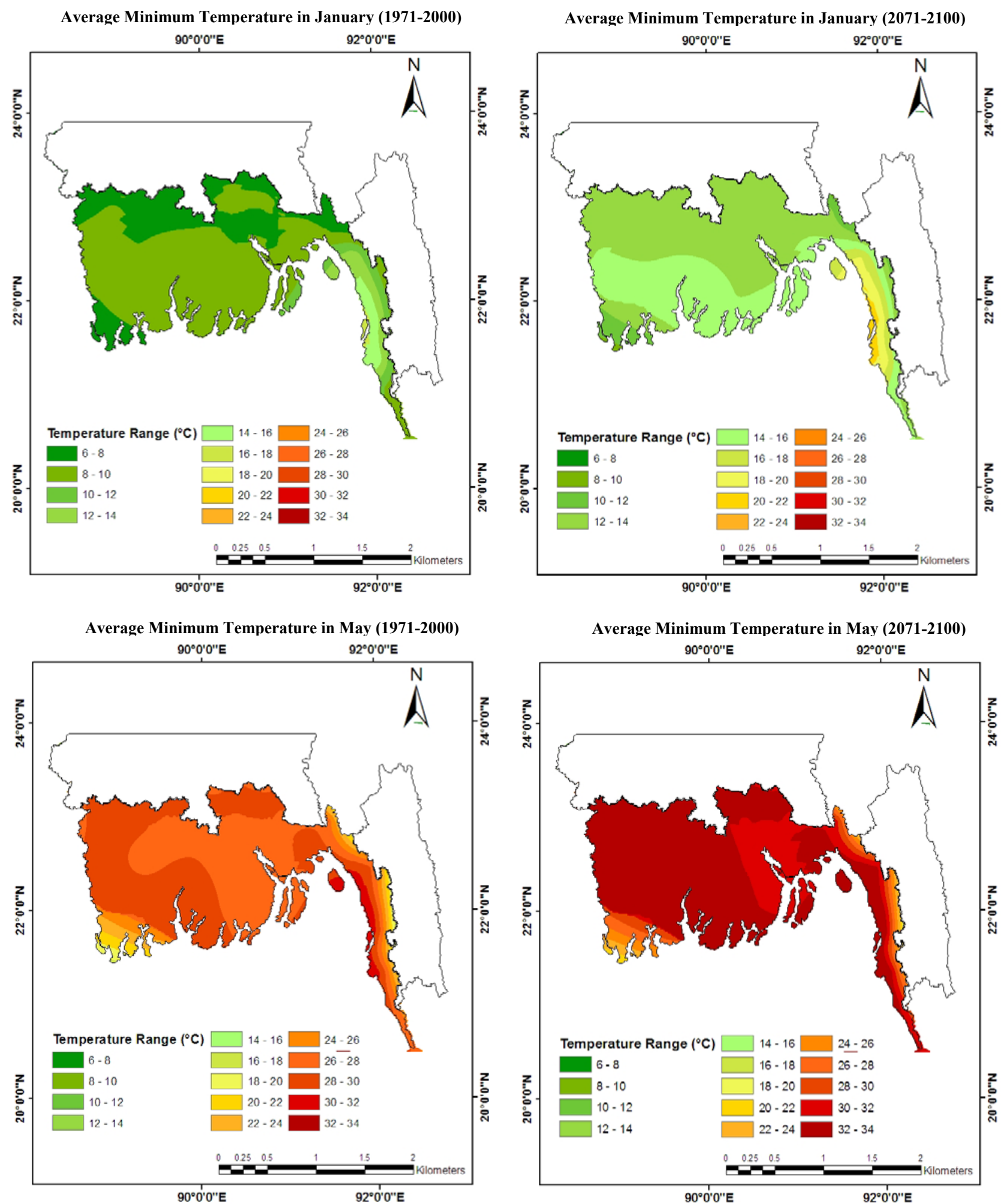

These plots are developed by ArcGIS with application of "Kriging". Kriging produces an estimate of the underlying (usually assumed to be smooth) surface by a weighted average of the data, with weights declining with distance between the point at which the surface is being estimated and the locations of the data points. Although the temporal analysis is based on a whole-country average, only 
the coastal region has been selected for inclusion in spatial analysis, because it is well apprehended that the coast is the most vulnerable part of Bangladesh, susceptible to climatic changes due to various hydroclimatic and geomorphologic reasons [34].

Importantly, the reason behind selecting May and January for spatial analysis is that they are the historically highest and lowest temperature months in Bangladesh. In the month of May, there is a distinct "east to west" pattern of increment in the average maximum temperature over the coastal region. In the north-western part of the coastal zone, the average maximum temperature in May can be as high as $42{ }^{\circ} \mathrm{C}$ in $2071-2100$ in comparison with that of 1971-2000, which was observed to be in a range of $38^{\circ} \mathrm{C}$. As exhibited from Figure 7, the minimum average temperature in January might change from $12{ }^{\circ} \mathrm{C}$ in $1971-2000$ to $14^{\circ} \mathrm{C}$ in $2071-2100$ along the southern fringes of the coast. Such a change in average minimum temperature is more extensive in the east coast belt. Having examined such a spatial variability of temperature change patterns, it is well understood that dissimilar temperature distribution all over the country should be taken into account in case of policy-intervention.

\section{Conclusions}

This paper features the future temperature scenario for Bangladesh being projected by the regional climate model PRECIS. The relevant modeling processes, such as domain size selection, bias identification, and calculation of change field are also addressed here. Therefore, less emphasis has so far been given to analyze the possible reasoning behind the speculative changes. The long term historical pattern of temperature in recent years as well as the RCM-predicted temperature trends evidence that there will be increasing temperature levels in Bangladesh through future times. From the results it can be inferred that the dry season months like December or January might have a greater amount of temperature change (around $5{ }^{\circ} \mathrm{C}$ in $2071-2100,0.5{ }^{\circ} \mathrm{C}$ per decade from 2011 onwards) with respect to 1971-2000, compared to the monsoon season months like July (around $3{ }^{\circ} \mathrm{C}$ in 2071-2100). Such an increasing trend of warming might prevail invariably in every month, which would therefore result in an average annual temperature rise of $4{ }^{\circ} \mathrm{C}$ by the year 2100 .

\section{Acknowledgements}

A.K.M. Saiful Islam, Institute of Water and Flood Management, BUET is gratefully acknowledged here for his assistance in developing the PRECIS projections. The authors are thankful to the Hadley Centre of UK Met Office for providing the PC-based PRECIS model with Lateral Boundary Condition data.

\section{References}

1. IPCC. Climate Change 2001: Impacts, Adaptation and Vulnerability: Contribution of Working Group II to the Third Assessment Report of the Intergovernmental Panel on Climate Change; McCarthy, J.J., Canziani, O.F., Leary, N.A., Dokken, D.J., White, K.S., Eds.; Cambridge University Press: Cambridge, UK, 2001.

2. Shahid, S. Spatial and temporal characteristics of droughts in the western part of Bangladesh. Hydrol. Process. 2008, 22, 2235-2247. 
3. Ramamasy, S.; Baas, S. Climate Variability and Change: Adaptation to Drought in Bangladesh; Asian Disaster Preparedness Centre and Food and Agriculture Organization of the United Nations: Rome, Italy, 2007.

4. IPCC. Climate Change 2001: The Scientific Basis: Contribution of Working Group I to the Third Assessment Report of the Intergovernmental Panel on Climate Change; Houghton, J.T., Ding, Y., Griggs, D.J., Noguer, M., van der Linden, P.J., Xioaosu, D., Eds.; Cambridge University Press: Cambridge, UK, 2001.

5. IPCC. Climate Change: Intergovernmental Panel on Climate Change; Houghton, J.T., Filho, L.G.M., Callander, B.A., Harris, N., Kattenberg, A., Maskell, K., Eds.; Cambridge University Press: Cambridge, UK, 1995.

6. Jones, R.G.; Noguer, M.; Hassell, D.C.; Hudson, D.; Wilson, S.S.; Jenkins, G.J.; Mitchell, J.F.B. Generating High Resolution Climate Change Scenarios Using PRECIS; Met Office Hadley Centre: Exeter, UK, 2004.

7. CCSP; Bader, D.C.; Covey, C.; Gutowski, W.J., Jr.; Held, I.M.; Kunkel, K.E.; Miller, R.L.; Tokmakian, R.T.; Zhang, M.H. Climate Models: An Assessment of Strengths and Limitations; A Report by the U.S. Climate Change Science Program and the Subcommittee on Global Change Research; Department of Energy, Office of Biological and Environmental Research: Washington, DC, USA, 2008.

8. Islam, M.N.; Rafiuddin, M.; Ahmed, A.U.; Kolli, R.K. Calibration of PRECIS in employing future scenarios in Bangladesh. Int. J. Climatol. 2008, 28, 617-628.

9. Islam, S.; Rehman, N.; Sheikh, M.M. Future change in the frequency of warm and cold spells over Pakistan by the PRECIS regional climate model. Climate Change 2009, 94, 35-45.

10. Rupa Kumar, K.; Sahai, A.K.; Krishna Kumar, K.; Patwardhan, S.K.; Mishra, P.K.; Revadekar, J.V.; Kamala, K.; Pant, G.B. High-resolution climate change scenarios for India for the 21 st century. Curr. Sci. 2006, 90, 334-345.

11. Basnayake, B.R.S.B.; Islam, M.N. Future Temperature Scenarios for Sri Lanka Using PRECIS for Assessing Climate Change Impacts and Vulnerability. In Proceedings of the International Conference on Climate Change Impacts and Adaptation Strategies for Bangladesh, Dhaka, Bangladesh, 18-19 February 2009; pp. 71-80.

12. IPCC; Giorgi, F.; Hewitson, B.; Christensen, J.; Hulme, M.; von Storch, H.; Whetton, P.; Jones, R.; Mearns, L.; Fu, C. Regional Climate Information-Evaluation and Projections. In Climate Change 2001: The Scientific Basis. Contribution of Working Group I to the TAR of the Intergovernmental Panel on Climate Change; Cambridge University Press: Cambridge, UK, 2001.

13. Simon, W.; Hassell, D.; Hein, D.; Jones, R.; Taylor, R. Installing and Using the Hadley Centre Regional Climate Modeling System, PRECIS Version 1.1; Met Office Hadley Centre: Exeter, UK, 2004.

14. Simmons, A.J.; Burridge, D.M. An energy and angular-momentum conserving finite difference scheme and hybrid co-ordinates. Mon. Weather Rev. 1981, 109, 758-766.

15. Gordon, C.; Cooper, C.; Senior, C.A.; Banks, H.; Gregory, J.M.; Johns, T.C.; Mitchell, J.F.B.; Wood, R.A. The simulation of SST, sea ice extents and ocean heat transports in a version of the Hadley Centre Coupled Model without flux adjustments. Climate Dyn. 2000, 16, 147-168. 
16. Ramaraj, A.P.; Jagannathan, R.; Dheebakaran, G.A. Assessing Predictability of PRECIS Regional Climate Model for Downscaling of Climate Change Scenarios. In Proceedings of the ISPRS Archives XXXVIII-8/W3 Workshop: Impact of Climate Change on Agriculture, Ahmedabad, India, 17-18 December 2009.

17. Tudor, M.; Termonia, P. Alternative formulations for incorporating lateral boundary data into Limited-Area Models. Mon. Weather Rev. 2010, 138, 2867-2882.

18. Miguez-Macho, G.; Stenchikov, G.L.; Robock, A. Regional climate simulations over North America: Interaction of local processes with improved large-scale flow. J. Climate 2005, 18, 1227-1246.

19. Qian, J.-H.; Zubair, L. The effect of grid spacing and domain size on the quality of ensemble regional climate downscaling over south Asia during the northeasterly monsoon. Mon. Wea. Rev. 2010, 138, 2780-2802.

20. Vannitsem, S.; Chomé, F. One-way nested regional climate simulations and domain size. J. Climate 2005, 18, 229-233.

21. Bhaskaran, B.; Jones, R.G.; Murphy, J.M.; Noguer, M. Simulations of the Indian summer monsoon using a nested Regional Climate Model: Domain size experiments. Climate Dyn. 1996, 12, 573-587.

22. Islam, A.K.M.S.; Bhaskaran, B.; Arifin, B.M.S.; Murshed, S.B.; Mukherjee, N.; Hossain, B.M.T.A. Domain Size Experiment Using PRECIS Regional Climate Model for Bangladesh. In Proceedings of the 3rd International Conference on Water and Flood Management, Dhaka, Bangladesh, 8-10 January 2011; Volume 2, pp. 891-898.

23. Nakicenovic, N.; Alcamo, J.; Davis, G.; de Vries, B.; Fenhann, J.; Gaffin, S.; Gregory, K.; Grübler, A.; Jung, T.Y.; Kram, T.; et al. Special Report on Emissions Scenarios; Cambridge University Press: Cambridge, UK \& New York, NY, USA, 2000.

24. Climate Change Cell (CCC). Generation of PRECIS Scenarios for Bangladesh (Validation and Parameterization); Department of Environment (DoE) and Ministry of Environment and Forests: Dhaka, Bangladesh, 2009.

25. Islam, M.N.; Rahman, M.A.; Ahsan, M.N. Long-Term Forecasting of Rainfall and Temperature in the SAARC Region Using RCM: Part I-Calibration; SAARC Meteorological Research Centre (SMRC): Dhaka, Bangladesh, 2009.

26. Uchiyama, T.; Mizuta, R.; Kamiguchi, K.; Kitoh, A.; Noda, A. Changes in temperature-based extremes indices due to global warming projected by a global $20-\mathrm{km}$-mesh atmospheric model. SOLA 2006, 2, 68-71.

27. Rajib, M.A.; Rahman, M.M.; Islam, A.K.M.S.; McBean, E.A. Analyzing the Future State of Monthly Precipitation Pattern in Bangladesh from Multi-Model Projections Using Both GCM and RCM. In Proceedings of the ASCE World Environmental \& Water Resources Congress, Palm Spring, CA, USA, 22-26 May 2011.

28. Rajib, M.A.; Rahman, M.M.; McBean, E.A. Application of regional climate model simulation and flow data for assessing future water availability in the River Jamuna. Int. J. Environ. Sci. 2011, 1, 884-896. 
29. Booty, W.G.; Lam, D.C.L.; Bowen, G.S.; Resler, O.; Leon, L. Modeling changes in stream water quality due to climate change in a southern Ontario watershed. Can. Water Resour. J. 2005, 30, 211-226.

30. Diaz-Nieto, J.; Wilby, R.L. A comparison of statistical downscaling and climate change factor methods: Impacts on low flows in the river Thames, United Kingdom. Climate Change 2005, 69, 245-268.

31. Zhang, X.C. Spatial downscaling of Global Climate Model output for site-specific assessment of crop production and soil erosion. Agric. For. Meteorol. 2005, 135, 215-229.

32. Christensen, J.H.; Hewitson, B. Regional Climate Projections. In Climate Change 2007: The Physical Science Basis: Contribution of Working Group I to the Fourth Assessment Report of the Intergovernmental Panel on Climate Change; Cambridge University Press: Cambridge, UK, 2007.

33. NCDC (National Climatic Data Center). Available online: http://www.ncdc.noaa.gov/cmb-faq/ anomalies.php (accessed on 24 May 2012).

34. Coastal Zone Policy (CZPo); Ministry of Water Resources: Dhaka, Bangladesh, 2005.

(C) 2012 by the authors; licensee MDPI, Basel, Switzerland. This article is an Open Access article distributed under the terms and conditions of the Creative Commons Attribution license (http://creativecommons.org/licenses/by/3.0/). 